\title{
Perbandingan Efektivitas Pemberian Efedrin Oral Dosis 25 mg dengan 50 mg Preoperatif terhadap Kejadian Hipotensi Pascaanestesi Spinal pada Seksio Sesarea
}

\author{
Selly Oktarina Rosita, ${ }^{1}$ Erwin Pradian, ${ }^{2}$ Ruli Herman Sitanggang ${ }^{2}$ \\ ${ }^{1}$ Rumah Sakit Umum Nurdin Hamzah Kab. Tanjung Jabung Timur-Jambi, ${ }^{2}$ Departemen Anestesiologi \\ dan Terapi Intensif Fakultas Kedokteran Universitas Padjadjaran/Rumah Sakit Dr. Hasan Sadikin \\ Bandung
}

\begin{abstract}
Abstrak
Tablet efedrin dapat mencegah hipotensi dengan efek samping lebih kecil. Penelitian ini bertujuan mengkaji dosis efektif tablet efedrin yang diberikan 30-45 menit sebelum dilakukan anestesi spinal untuk menurunkan kejadian hipotensi. Penelitian bersifat eksperimental acak tersamar tunggal dengan 32 ibu hamil ASA II yang menjalani operasi sesar dengan anestesi spinal di Rumah Sakit Dr. Hasan Sadikin Bandung pada bulan Maret-Mei 2012. Subjek penelitian dikelompokkan menjadi dua, yaitu kelompok efedrin $25 \mathrm{mg}$ dan $50 \mathrm{mg}$. Data dianalisis dengan Uji Mann Whitney dan chi-kuadrat, nilai $\mathrm{p}<0,05$ dianggap bermakna. Analisis statistik menunjukkan bahwa kejadian hipotensi pada kelompok efedrin $25 \mathrm{mg}$ dan kelompok $50 \mathrm{mg}$ berbeda bermakna $(\mathrm{p}=0,049)$. Pada kelompok tablet efedrin $25 \mathrm{mg}$ kebutuhan efedrin intravena pascaanestesi spinal lebih besar $(\mathrm{p}=0,040)$. Simpulan penelitian ini adalah pemberian tablet efedrin 50 mg 30-45 menit sebelum anestesi spinal dapat mencegah hipotensi pascaanestesi spinal lebih baik dibandingkan dengan tablet efedrin 25 mg. Kelompok tablet efedrin 25 mg memerlukan jumlah pemberian efedrin intravena lebih banyak dibandingkan dengan kelompok tablet efedrin $50 \mathrm{mg}$.
\end{abstract}

Kata kunci: Anestesi spinal, seksio sesarea, efedrin oral, hipotensi

\section{Comparison of the Effectiveness of Pre operative Oral 25 mg with 50 mg Ephedrine on Post spinal Anaesthesia Hypotension in Caesarean Section}

\begin{abstract}
Oral ephedrine is one alternative to prevent hypotension with less adverse effects. The purpose of this study was to determine the effective dose of oral ephedrine given 30-45 minutes before spinal anesthesia to reduce incidence of hypotension. The research was a single-blind randomized experimental study involving 32 pregnant women, ASA II, who underwent caesarean section with spinal anesthesia at Dr. Hasan Sadikin Hospital Bandung from March to May 2012. Subjects were divided into two groups, $25 \mathrm{mg}$ ephedrine and $50 \mathrm{mg}$ ephedrine groups. Data was analyzed using Mann Whitney and chi-square test, $\mathrm{p}<0.05$ was considered significant. Statistical analysis showed there was a significant difference $(\mathrm{p}=0.049)$ in incidence of hypotension between $25 \mathrm{mg}$ group and $50 \mathrm{mg}$ group. $25 \mathrm{mg}$ group required more intravenous ephedrine after spinal anesthesia $(\mathrm{p}=0.040)$. The conclusion of this study was that oral $50 \mathrm{mg}$ ephedrine given $30-45$ minutes before performing spinal anesthesia will reduce the incidence of hypotension after spinal anesthesia in comparison to oral $25 \mathrm{mg}$ ephedrine. In $25 \mathrm{mg}$ group, the amount of ephedrine intravenous administered is higher compared with $50 \mathrm{mg}$ group.
\end{abstract}

Key words: Spinal anesthesia, oral ephedrine, caesarean section, hypotension

Korespondensi: Selly Oktarina Rosida, dr., SpAn, M.Kes, RSU Nurdin Hamzah, Jl. WR Supratman Kel. Parit Culum I, Keramas, Muara Sabak Barat, Kab. Tanjung Jabung Timur-Jambi, mobile 0812-7802200, email selly_or@yahoo.com 


\section{Pendahuluan}

Anestesi regional spinal adalah teknik anestesi regional yang banyak dipilih pada pasien yang akan menjalani seksio sesarea. Anestesi spinal sangat popular dikerjakan karena onset cepat serta memberikan blok sensorik dan motorik berkualitas tinggi. ${ }^{1}$

Anestesi spinal yang dilakukan pada wanita hamil berkaitan dengan angka kejadian efek samping hipotensi yang tinggi. Tekanan darah setelah anestesi spinal kira-kira menurun 39$45 \%$, hal ini dikarenakan level blokade simpatis yang lebih tinggi apabila dibandingkan dengan wanita tidak hamil yang berkaitan erat dengan penekanan pada aortokaval akibat uterus yang membesar serta resistensi vaskular sistemik yang memang sudah mengalami penurunan karena proses kehamilan. ${ }^{2}$

Pada penelitian tahun 2001, menunjukkan angka kejadian hipotensi pada seksio sesarea akibat anestesi spinal mencapai 80\%, hal ini terjadi walaupun telah dilakukan pemberian preload cairan, lateral uterine displacement, dan juga penggunaan vasopresor sebelumnya. Penelitian pada tahun 2002 juga melaporkan bahwa komplikasi akibat anestesi spinal yang sering pada seksio sesarea adalah hipotensi, dengan angka kejadian lebih dari $80 \% .^{3}$ Pada penelitian tahun 2004 juga dilaporkan angka kejadian komplikasi hipotensi pada kelompok kontrol yang menjalani seksio sesarea dengan anestesi spinal tanpa intervensi adalah $92 \%{ }^{4}$

Hipotensi yang tidak diatasi segera dapat menimbulkan beberapa komplikasi baik pada ibu maupun janin. Hipotensi pada ibu hamil dapat menyebabkan terjadi mual dan muntah, bahkan pada beberapa kasus hipotensi berat dapat mengakibatkan penurunan kesadaran, aspirasi pulmonal, depresi sistem pernapasan, bahkan henti jantung. Mual muntah serta lightheadedness pada ibu yang mengalami hipotensi disebabkan karena penurunan aliran darah serebral. Kondisi ini menyebabkan morbiditas pada ibu. Teknik yang sering digunakan untuk mencegah hipotensi adalah leg elevation and compression, preloading atau coloading, uterine displacement, mengurangi dosis anestesi lokal, serta pemberian vasopresor. ${ }^{5}$ Suatu survei di Inggris menunjukkan bahwa lebih dari 95\% dokter anestesi menggunakan efedrin untuk mengatasi hipotensi yang disebabkan anestesi spinal pada seksio sesarea elektif. ${ }^{6}$

Efedrin adalah obat lama yang tersedia dan dikenal oleh kebanyakan ahli anestesi. Selama penggunaan beberapa dekade di kebidanan, hanya sedikit laporan mengenai efek samping terhadap ibu maupun bayi. Efedrin merupakan obat golongan nonspesifik agonis adrenergik yang bekerja paling kuat pada $\beta_{1}$ adrenoseptor jantung dengan meningkatkan curah jantung serta laju nadi sehingga tekanan darah menjadi stabil. Efedrin dapat mempertahankan aliran darah uteroplasental tetap mencukupi untuk menjaga tekanan darah maternal karena kerja pada reseptor $\alpha$ adrenergik yang tidak kuat. ${ }^{1,6}$ Rute pemberian dan dosis efedrin yang tepat untuk mencegah terjadi hipotensi akibat spinal selama seksio sesarea masih kontroversi.

\section{Subjek dan Metode}

Penelitian ini bertujuan mengkaji penggunaan efedrin oral dosis $50 \mathrm{mg}$ dibandingkan dengan dosis 25 mg yang diberikan sebelum dilakukan anestesi spinal untuk menurunkan kejadian hipotensi setelah anestesi spinal pada seksio sesarea.

Subjek penelitian yaitu wanita hamil yang menjalani prosedur seksio sesarea di Rumah Sakit Dr. Hasan Sadikin (RSHS) Bandung yang memenuhi kriteria inklusi dan tidak termasuk dalam kriteria eksklusi. Kriteria inklusi adalah pasien wanita hamil aterm dengan usia 20-35 tahun, direncanakan seksio sesarea dengan anestesi spinal, status fisik ASA II (American's Society of Anesthesiologist). Kriteria eksklusi adalah pasien dengan tinggi badan $<145 \mathrm{~cm}$, kehamilan risiko tinggi, janin $>1$, hipertensi dalam kehamilan, penderita hipotensi (tekanan darah sistol $<90 \mathrm{mmHg}$ ), serta kontraindikasi dilakukan anestesi spinal, alergi obat anestesi lokal dan efedrin. Kriteria pengeluaran apabila terjadi kegagalan pada tindakan spinal setelah ditunggu selama 15 menit atau seksio sesarea yang berakhir dengan histerektomi. 
Jenis penelitian ini adalah eksperimental dengan melakukan uji klinis rancangan acak lengkap terkontrol buta tunggal (single blind randomized controlled trial). Jumlah sampel ditentukan menggunakan formula uji hipotesis dua rata-rata, sehingga didapatkan total sampel 32 orang terdiri atas 16 orang per kelompok. Analisis statistik data hasil penelitian ini menggunakan uji-t tidak berpasangan apabila data normal, Uji Mann-Whitney apabila data tidak normal, serta dilakukan uji-chi kuadrat untuk tipe data kategorik, dengan memakai tingkat kepercayaan 95\% dan hasil dianggap bermakna bila $\mathrm{p}<0,05$. Data ditampilkan dalam rata-rata (mean), kemudian dianalisis dengan menggunakan program statistical product and servise solution (SPSS) 17,0 for windows.

Pasien dibagi dua kelompok, pada kelompok I diberikan $25 \mathrm{mg}$ efedrin 30 menit sebelum dilakukan anestesi spinal sedangkan kelompok II diberi efedrin $50 \mathrm{mg}$ saat 30 menit sebelum dilakukan anestesi spinal. Cairan preloading Ringer laktat diberikan $15 \mathrm{~mL} / \mathrm{kgBB}$ dalam waktu 15 menit; kemudian dilakukan anestesi spinal memakai $2 \mathrm{~mL}$ bupivakain heavy 0,5\% yang ditambahkan fentanil $25 \mathrm{mcg}$. Setelah itu, dilakukan penilaian kualitas blokade sensorik dan motorik.
Variabel hemodinamik diukur setiap menit selama 15 menit yang pertama dan setelah itu setiap 3 menit sampai akhir operasi. Selama kejadian operasi, hipotensi, bradikardia, mual, muntah, menggigil, dan efek samping lainnya dicatat. Apabila terjadi hipotensi diberikan bolus efedrin dosis $5 \mathrm{mg}$ intravena, sedangkan penanganan bila bradikardia diberikan atropin intravena dosis 0,5 mg. Dilakukan pencatatatan jumlah cairan, efedrin, dan juga sulfas atropin yang digunakan selama operasi. Setelah bayi lahir, diberikan tetesan oksitosin 20 IU dalam $500 \mathrm{~mL}$ cairan Ringer laktat sebanyak 10-15 tetes per menit. Penelitian dilakukan di kamar operasi RSHS Bandung dari bulan Maret-Mei 2012.

\section{Hasil}

Hasil uji statistik dengan Uji Mann-Whitney menggunakan nilai derajat kepercayaan 95\% terhadap karakteristik usia, berat badan, tinggi badan, tekanan darah sebelum anestesi spinal, lama operasi, lama puasa, jumlah perdarahan, dan juga tinggi blokade anestesi spinal antara kelompok efedrin tablet $25 \mathrm{mg}$ dan $50 \mathrm{mg}$ menunjukkan perbedaan yang tidak bermakna

Tabel Karakteristik Subjek Penelitian Kedua Kelompok Perlakuan

\begin{tabular}{lccccc}
\hline \multirow{2}{*}{\multicolumn{1}{c}{ Karakteristik }} & \multicolumn{2}{c}{$\begin{array}{c}\text { Efedrin Tablet } \mathbf{2 5} \mathbf{~ m g} \\
(\mathbf{n = 1 6})\end{array}$} & \multicolumn{2}{c}{$\begin{array}{c}\text { Efedrin Tablet 50 mg } \\
\text { (n=16) }\end{array}$} & \\
\cline { 2 - 6 } & Rata-rata & SD & Rata-rata & SD & \\
\hline Usia (tahun) & 28,00 & 6,21 & 28,63 & 4,92 & 0,691 \\
Berat badan (kg) & 64,56 & 7,09 & 67,44 & 7,88 & 0,168 \\
Tinggi badan (cm) & 155,00 & 3,54 & 155,25 & 3,89 & 0,909 \\
Tekanan darah sistol & 121,63 & 5,90 & 124,63 & 8,55 & 0,308 \\
praanestesi spinal (mmHg, t0) & & & & & \\
Lama operasi (menit) & 47,75 & 8,47 & 52,69 & 9,57 & 0,055 \\
Lama puasa (jam) & 6,375 & 1,82 & 6,75 & 1,53 & 0,428 \\
Perdarahan (mL) & 640,63 & 89,85 & 675,00 & 101,65 & 0,340 \\
Tinggi blok & 7 & & & & 0,325 \\
T5 & 7 & & 7 & & \\
T6 & 2 & & 0 & & \\
T7 & 7 &
\end{tabular}

Keterangan: Nilai p pada variabel tinggi blok dihitung berdasarkan uji chi-kuadrat. Nilai p dihitung berdasarkan Uji Mann-Whitney (karena data tidak normal). Nilai p bermakna $(p<0,05)$ 
( $p>0,05)$. Hal ini menunjukkan bahwa variabel pengganggu yang dapat memengaruhi hasil penelitian ini dapat disingkirkan sehingga menurut statistik subjek yang diteliti adalah homogen dan layak dibandingkan (Tabel).

Hasil uji statistik menggunakan uji chikuadrat pada nilai derajat kepercayaan 95\% menunjukkan angka kejadian hipotensi pada kelompok tablet efedrin $25 \mathrm{mg}$ lebih besar secara bermakna $(p=0,049)$, yaitu sebanyak 7 dari 16 orang, sedangkan pada kelompok tablet efedrin 50 mg sebanyak 2 dari 16 orang (Gambar 1). Pasien tersebut mendapat efedrin intravena $5 \mathrm{mg}$ hingga tekanan darah sistol kembali di atas $90 \mathrm{mmHg}$.

Hasil Uji Mann-Whitney pada nilai derajat kepercayaan 95\% menunjukkan penurunan tekanan darah sistol dan diastol, serta tekanan darah rata-rata pada kelompok tablet efedrin $25 \mathrm{mg}$ lebih tinggi secara bermakna apabila dibandingkan dengan kelompok tablet efedrin 50 mg ( $<<0,05$; Gambar 2, 3, 4).

Laju nadi rata-rata pada kelompok tablet efedrin $25 \mathrm{mg}$ lebih tinggi bila dibandingkan dengan kelompok tablet efedrin $50 \mathrm{mg}$, namun berdasarkan uji statistik menggunakan Uji Mann- Whitney pada nilai derajat kepercayaan 95\% ternyata perbedaan laju nadi tersebut tidak bermakna $(p>0,050)$.

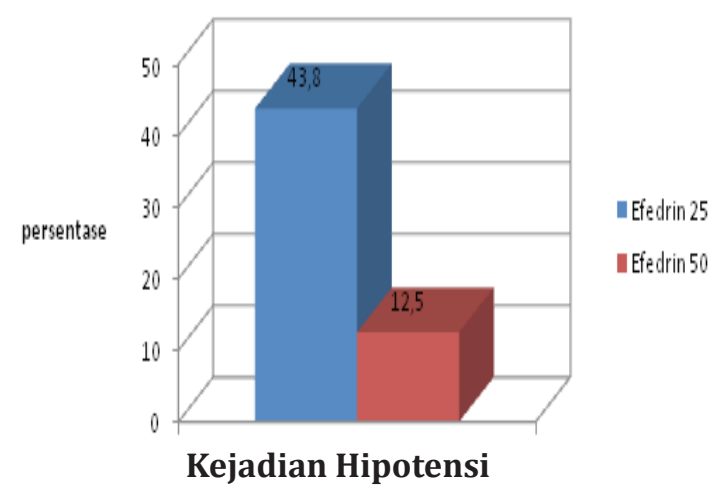

Gambar 1 Perbandingan Angka Kejadian Hipotensi antara Pemberian Tablet Efedrin $25 \mathrm{mg}$ dan $50 \mathrm{mg}$ 30-45 Menit Sebelum Dilakukan Anestesi Spinal

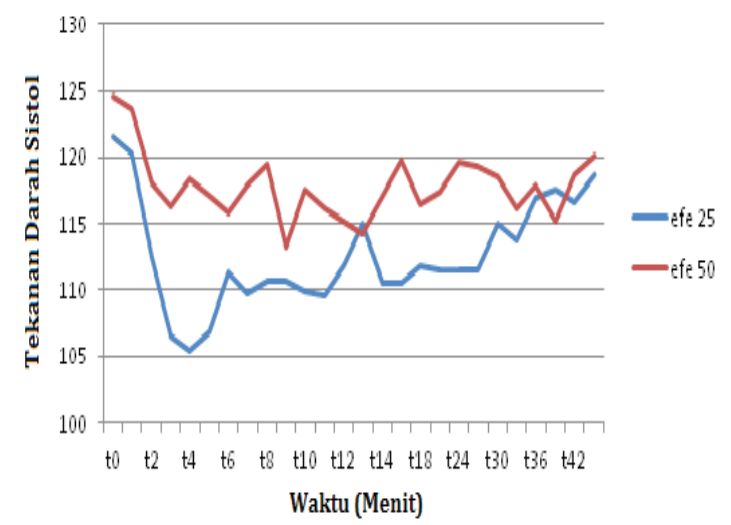

Gambar 2 Perbandingan Tekanan Darah Sistol antara Pemberian Tablet Efedrin 25 mg dan 50 mg 30-45 Menit Sebelum Dilakukan Anestesi Spinal

Kebutuhan efedrin intravena rata-rata yang diberikan untuk mengatasi kejadian hipotensi pada kelompok tablet efedrin 25 mg adalah 3,1 mg dengan simpangan deviasi 4,03, sedangkan pada kelompok tablet efedrin 50 mg sebesar $0,6 \mathrm{mg}$ dengan simpangan deviasi 1,71. Hasil Uji Mann-Whitney dengan derajat kepercayaan 95\% menunjukkan bahwa terdapat perbedaan bermakna pemberian efedrin intravena untuk

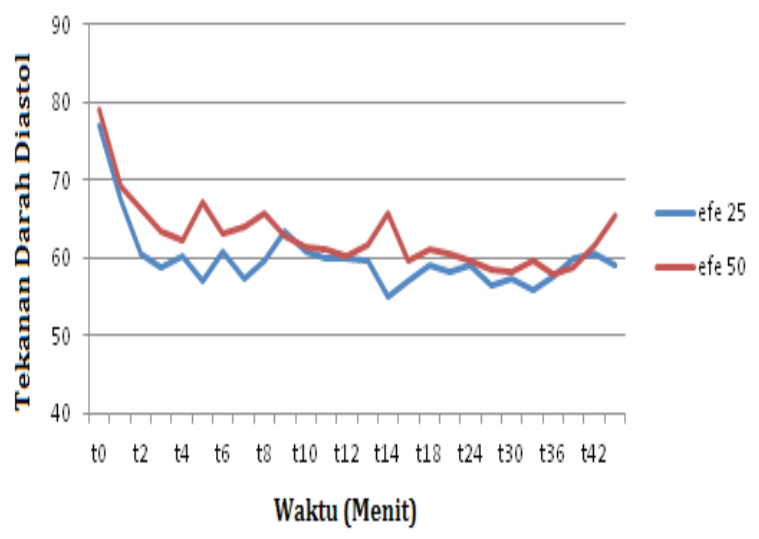

Gambar 3 Perbandingan Tekanan Darah Diastol antara Pemberian Tablet Efedrin $25 \mathrm{mg}$ dan $50 \mathrm{mg}$ 30-45 Menit Sebelum Dilakukan Anestesi Spinal 


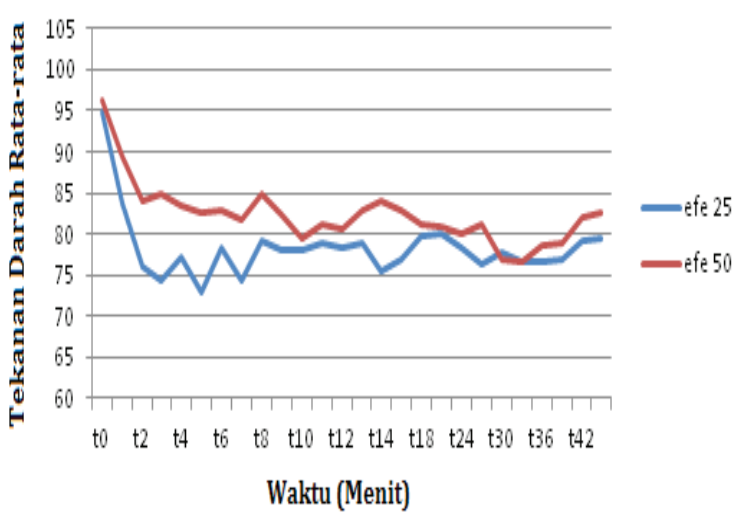

Gambar 4 Perbandingan Tekanan Darah Ratarata antara Pemberian Tablet Efedrin 25 mgdan 50 mg 30-45 MenitSebelum Dilakukan Anestesi Spinal

mengatasi kejadian hipotensi antara kelompok efedrin $25 \mathrm{mg}$ dan efedrin $50 \mathrm{mg}(\mathrm{p}=0,040)$.

\section{Pembahasan}

Hipotensi diperkirakan terjadi pada sepertiga pasien yang mendapatkan tindakan anestesi spinal. Hipotensi akibat anestesi spinal dapat diperbaiki secara fisiologis dengan pengisian kembali aliran darah balik untuk meningkatkan curah jantung. Hidrasi yang adekuat sebelum anestesi spinal dilakukan merupakan tindakan penting untuk mengurangi efek venodilatasi akibat penghambatan sistem saraf simpatis.

Pencegahan hipotensi dapat pula dilakukan dengan penyuntikan obat anestesi lokal spinal secara lambat, pemberian cairan intravena secara cepat, serta penggunaan alat kompresi kaki. ${ }^{5}$ Meskipun sudah dilakukan penanganan secara konservatif, angka kejadian hipotensi masih tetap tinggi antara $80 \%$ sampai $95 \%$. Untuk memperbaiki kondisi ini diindikasikan untuk penggunaan agen vasoaktif. Efedrin telah menjadi agen vasoaktif utama pada anestesi pasien obstetrik yang dapat mempertahankan aliran darah arteri uterus dan juga $\mathrm{pH}$ fetus, sehingga pemakaian efedrin masih berperan dalam anestesi obstetrik untuk mencegah atau

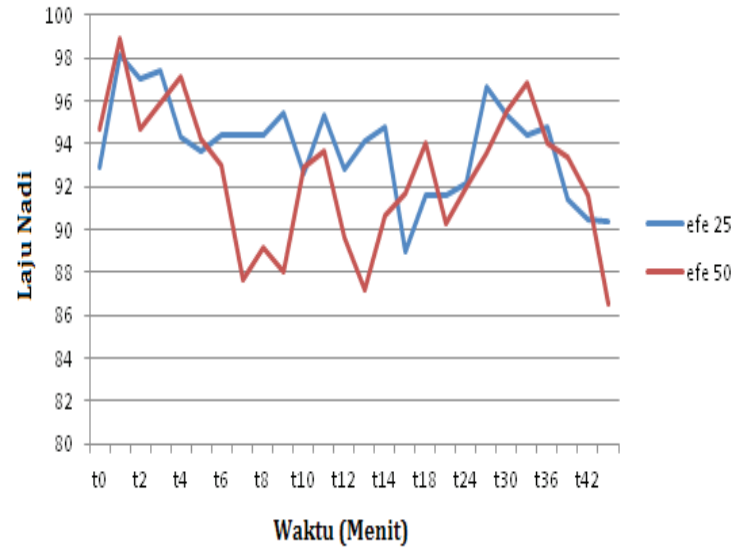

Gambar 5 Perbandingan Laju Nadi antara Pemberian Tablet Efedrin 25 mg dan 50mg30-45menitSebelumDilakukan Anestesi Spinal

mengatasi hipotensi akibat anestesi spinal bila diberikan dalam dosis yang tepat. ${ }^{5}$

Penelitian sebelum ini telah membuktikan bahwa efedrin oral dosis $25 \mathrm{mg}, 30 \mathrm{mg}, 50 \mathrm{mg}$, dan dosis $0,6 \mathrm{mg} / \mathrm{kgBB}$ yang diberikan $30-45$ menit sebelum anestesi spinal dapat mencegah kejadian hipotensi. Namun, penelitian tersebut hanya membandingkan preparat efedrin tablet dengan plasebo ataupun dengan pemberian intramuskular, tetapi tidak membandingkan pemberian preparat tablet dengan beberapa dosis. ${ }^{8,9}$ Hasil analisis data karakteristik umum pasien antara kedua kelompok perlakuan tidak menunjukkan perbedaan bermakna $(p>0,05)$ dalam hal distribusi karakteristik, sehingga kedua kelompok layak untuk diperbandingkan (Tabel).

Ketinggian blokade juga akan memengaruhi derajat serta insidensi hipotensi. Ketinggian blok setinggi vetebra servikal, ternyata tingkat hipotensi akan lebih berat bila dibandingkan dengan anestesi setinggi vetebra torakal. Pada penelitian ini ketinggian blok yang ditolerir hanya sampai ketinggian blok torakal 5 sampai torakal 7. Ketinggian blokade di atas torakal 5 atau di bawah torakal 7 akan dikeluarkan dari penelitian, karena blokade di bawah torakal 7 menyebabkan ibu masih merasakan nyeri saat 
manipulasi operasi, sedangkan ketinggian di atas torakal 4 akan berpotensi menimbulkan bradikardia. ${ }^{11}$

Pada penelitian ini diperhitungkan usaha untuk menghomogenisasi faktor yang dapat memengaruhi hemodinamik akibat tindakan anestesi spinal dan tindakan operasi, sehingga didapatkan ketinggian blok, lama operasi, dan juga jumlah perdarahan pada kedua kelompok dianggap homogen secara statistik $(p>0,05)$.

Hasil pemeriksaan tekanan darah dan juga laju nadi sebelum dilakukan anestesi spinal tidak berbeda bermakna menurut statistik. Kedua kelompok ini memiliki karakteristik hemodinamik yang sama.

Pada kelompok efedrin $25 \mathrm{mg}$, terdapat 7 dari 16 orang pasien yang dilakukan seksio sesarea mengalami hipotensi dengan ditandai penurunan tekanan darah sistol sebesar 20\% dari nilai tekanan darah sistol awal. Pasien ini ditangani dengan pemberian efedrin intravena 5 mg hingga tekanan darah sistol kembali normal (di atas $90 \mathrm{mmHg}$ ). Pada kelompok 50 mg hanya terdapat 2 (dua) orang pasien yang mengalami kejadian hipotensi. Perbandingan angka insiden hipotensi ini menunjukkan hasil yang bermakna secara statistik $(\mathrm{p}=0,005)$.

Pada penelitian ini, tekanan darah sistol rata-rata lebih rendah secara statistik pada kelompok kontrol tablet efedrin dosis $25 \mathrm{mg}$ bila dibandingkan dengan kelompok perlakuan tablet efedrin $50 \mathrm{mg}$. Perbedaan tekanan darah sistol ini secara statistik bermakna pada menit ke-3, 4, 5, 8, 15, 24, dan menit ke-27. Tekanan darah sistol kedua kelompok tampak bahwa hemodinamik pada pasien kelompok tablet efedrin $50 \mathrm{mg}$ lebih baik bila dibandingkan dengan kelompok tablet efedrin $25 \mathrm{mg}$. Begitu pula tekanan darah arteri dan tekanan darah diastol rata-rata pada kelompok kontrol tablet efedrin $25 \mathrm{mg}$ juga lebih rendah dibandingkan dengan nilai kelompok perlakuan. Perbedaan tekanan darah ini juga secara statistik dinilai bermakna pada menit ke-5 dan ke-14 untuk tekanan darah diastol dan pada menit ke-3, 5, dan ke-15 untuk tekanan darah rata-rata. Hasil ini menunjukkan bahwa pada pemberian tablet efedrin 50 mg 30-45 menit sebelum dilakukan anestesi spinal dapat mencegah penurunan tekanan darah yang lebih baik dibandingkan dengan pemberian tablet efedrin $25 \mathrm{mg}$.

Pada penelitian ini tidak terjadi perubahan laju nadi yang besar pada kedua kelompok. Perbedaan laju nadi pada kedua kelompok menunjukkan hasil yang tidak berbeda secara statistik Salah satu efek samping pemberian tablet efedrin yaitu takikardia. Pada penelitian ini peningkatan laju nadi tidak jauh berbeda, sehingga tidak perlu ditakutkan penggunaan tablet efedrin dosis besar, dalam hal ini dosis $50 \mathrm{mg}$. Salah satu yang memengaruhi laju nadi adalah tingkat kecemasan pasien. Pada penelitian ini kedua kelompok memiliki tingkat kecemasan yang tidak berbeda bermakna.

Pemberian tablet efedrin per oral sebelum dilaksanakan anestesi spinal mengharapkan efek kardiovaskular yang akan meningkatkan tekanan darah sistol, diastol, dan tekanan nadi. Peningkatan sistol lebih besar daripada diastol yang sebagian disebabkan oleh vasokonstriksi, tetapi terutama karena stimulasi jantung yang meningkatkan kekuatan kontraksi ototjantung serta curah jantung. Denyut jantung mungkin tidak akan berubah akibat refleks kompensasi vagal terhadap kenaikan tekanan darah. Efek tersebut tampak nyata jika diberikan selain per oral.

Efedrin intravena diberikan bila terdapat penurunan pada tekanan darah sistol 20\% dari tekanan darah sistol praanestesi spinal. Hasil penelitian ini menunjukkan bahwa kebutuhan pemberian efedrin yang berbeda bermakna antara dua kelompok, kelompok tablet efedrin $25 \mathrm{mg}$ membutuhkan efedrin intravena lebih banyak untuk meningkatkan tekanan darah selama operasi. Efek samping yang didapatkan pada penelitian ini berupa mual, bradikardia, takikardia, hipertensi, serta menggigil dengan perbedaan yang tidak bermakna.

\section{Simpulan}

Simpulan penelitian ini, bahwa angka kejadian hipotensi pada penggunaan efedrin oral dosis $50 \mathrm{mg}$ sebelum dilakukan anestesi spinal pada seksio sesarea lebih kecil apabila dibandingkan dengan efedrin oral dosis $25 \mathrm{mg}$. Pemberian tablet efedrin dosis $25 \mathrm{mg}$ sebelum dilakukan 
anestesi spinal memerlukan jumlah efedrin intravena rata-rata lebih besar dibandingkan dengan kelompok tablet efedrin $50 \mathrm{mg}$. Laju nadi pada kelompok tablet efedrin $25 \mathrm{mg}$ dan $50 \mathrm{mg}$ tidak berbeda pada kedua kelompok.

\section{Daftar Pustaka}

1. Varathan S, Ekanayake SU, Amarasinghe U. Comparison of prophylactic intramuscular efedrin with preloading versus preloading alone in prevention of hypotension during elective caesarean section under subarachnoid block. Sl J Anaesth. 2009;17(2):55-60.

2. Myanroudi MH, Alizadeh K, Sadeghi M. Hypotension in spinal and epidural anestesi. Bahrain Med Bull. 2008;30:1-5.

3. Baraka A. Can we minimize hypotension following anaesthesia spinal for caesarean section. Middle East J Anesth. 2010;20(5):619-20.

4. Bhagat H, Malhotra K, Ghildyal SK, Srivastava PC. Evaluation of preloading and vasoconstrictors as a combined prophylaxis for hypotension during subarachnoid anaesthesia. Indian J Anaesth. 2004;48(4):29-303.

5. Australian and New Zealand College of Anaesthetists. Hypotension during regional anaesthesia for caesarean birth. (diunduh 20 Juni 2011). Tersedia dari: www.accec.org

6. Halpern $\mathrm{SH}$, Chochinov $\mathrm{M}$. The use of vasopressors for the prevention and treatment of hypotension secondary to regional anaesthesia for caesarean section. Dalam: Halpern SH, Douglas MJ, penyunting. Evidence base obstetric anesthesia. Edisi ke-1. Canada: Blackwell Publishing; 2005. hlm. 101-6.

7. Macarthur A, Riley ET. Obstetric anaesthesia controversies: vasopressor choice for postspinal hypotension during cesarean delivery. Departement of anesthesiology and pain management, University Health Network and the Department of Anesthesiology. Int Anesthesiol Clin. 2007;45(1):115-32.

8. Eroglu F, Yafuz L, Ceylan BG, Sevin G, Soyupek S. Prophylactic effects of systemic oral efedrin in anestesi spinalinduced hypotension during transurethral prostatectomy. Scand J Urol Nephrol. 2003;37:145-50.

9. Chohedri AH, Khojeste L, Shahbazi S, Alahyari E. Efedrin for prevention hypotension; comparison between intravenous, intramuscular and oral administration during anaesthesia spinal for elective caesarean section. Professional Med J. 2007;14(4):610-5.

10. Bernard C. Complication of regional anesthesia. Dalam: Mulroy M, Bernard CM, Mc Donald SB, Salinas FV, penyunting. A practical approach to regional anesthesia. Edisi ke-4. Baltimore: Lippincott Williams \& Wilkins; 2009. hlm. 24-38. 